\title{
PENGARUH ALOE VERA PADA TRANSMITANSI ULTRASONIK GEL KARBOMER 940
}

\author{
M.Rosyid Ridlo \\ Pusat Penelitian Fisika LIPI, Kawasan Puspiptek, \\ Serpong Tangerang Selatan \\ E-mail:mrridlo@yahoo.com
}

\begin{abstract}
On examination using USG ( ultrasonography), gel carbomer 940 applied on body surface has role as acoustic coupling agent between USG probe and body surface. The function of this gel is to transmit ultrasonics wave from probe to body without resisted by the air. Gel carbomer 940 is a non biodegradable matter. For decreasing the content of non biodegradable part of carbomer 940, in this research, the extract of aloe vera was added into gel carbomer 940. To know the efficiency of ultrasonics energy tramsmitted to the body, transmitansi coefficient measurement is required.. Transmitansi coefficient can be calculated from ultrasonics velocity value in the gel. The velocity measurement use transmit time method with equipment the ultrasonics thickness gauge AR860 connected to osciloscope. Examanation of the coefficient was carried out in first and 12 th week. The results indicated the acoustic impedance and the transmitansi coefficient decreased by adding of aloevera content. However at 12 th week the influence of aloe vera relatively did not give effect to the gel carbomer transmittance.
\end{abstract}

Keywords : Aloevera, Gel Carbomer, Transmitance, Acoustic Impedance.

\section{PENDAHULUAN}

Pada pemeriksaan menggunakan alat USG, perlu dioleskan pada permukaan tubuh suatu medium (acoustic copling agent) yang berbentuk gel. Dengan gel tersebut gelombang ultrasonik dapat ditransmisikan secara efisien dari probe ultrasonik ke tubuh pasien (McDicken, 1976) (Susan, 2012). Di pasaran bahan gel yang digunakan adalah berbasis carbomer 940 (C3H4O2). Bahan ini tergolong non biodegradeble yang dapat berarti tidak ramah lingkungan (Christine, 2006). Dalam penelitian ini, kadar non biodegradeble dalam kandungan gel akan dikurangi dengan cara menambahkan sari lidah buaya (aloe vera). Secara medis pun, aloe vera memiliki banyak manfaat diantaranya pendorong pertumbuhan sel yang baru yang sebelumnya rusak karena luka (Vogler, 1999). Penelitian ini akan menguji karakteristik ultrasonik dari efek penambahan aloe vera pada gel tersebut, khususnya pada koefisien transmisinya.
Efisiensi energi yang dipancarkan dari probe ultrasonik ke tubuh dapat diketahui dari parameter ultrasonik ini.

\section{METODE PENELITIAN}

Dari pelepah daun aloe vera diambil daging atau gel nya yang selanjutnya dilakukan blenching untuk menghilangkan getahnya. Kemudian daging / gel di blender dan diambil cairan sarinya dengan cara disaring. Cairan ini lalu ditambahkan ke material carbomer 940 berdasar persen volume $25 \%, 40 \%$ dan $55 \%$. Pada tiap - tiap komposisi pencampuran dilakukan pengukuran cepat rambat ultrasonik (C) dan densitas bahan tersebut. Dari cepat rambat ultrasonik dan densitas dapat dihitung nilai impedansi akustik $\mathrm{Z}$ dan juga koefisien transmisi $\mathrm{T}$ melalui hubungan matematis (Krautkramer, 1990).

$Z=\rho . C$. 


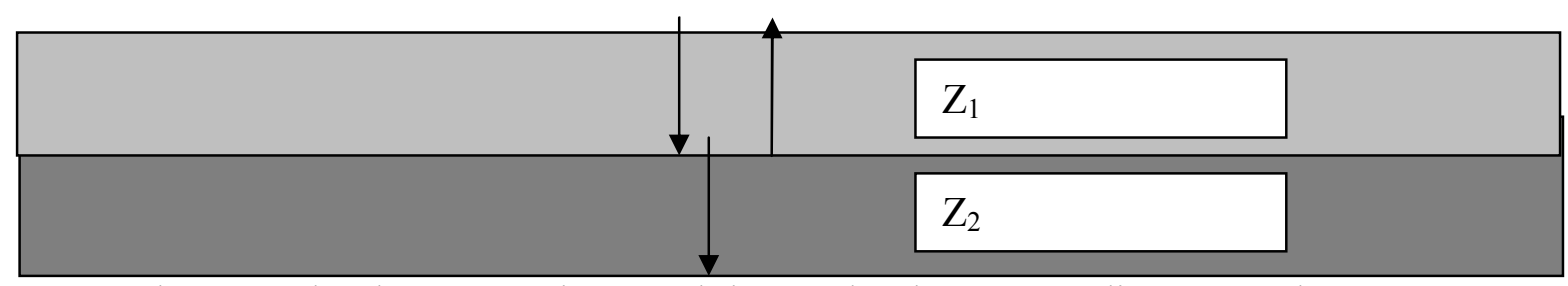

Gambar 1. Gelombang Masuk, Pantul dan Gelombang yang di Terus Pada Batas Dua

Medium Dengan Impedansi Akustik $Z_{1}$ dan $Z_{2}$.

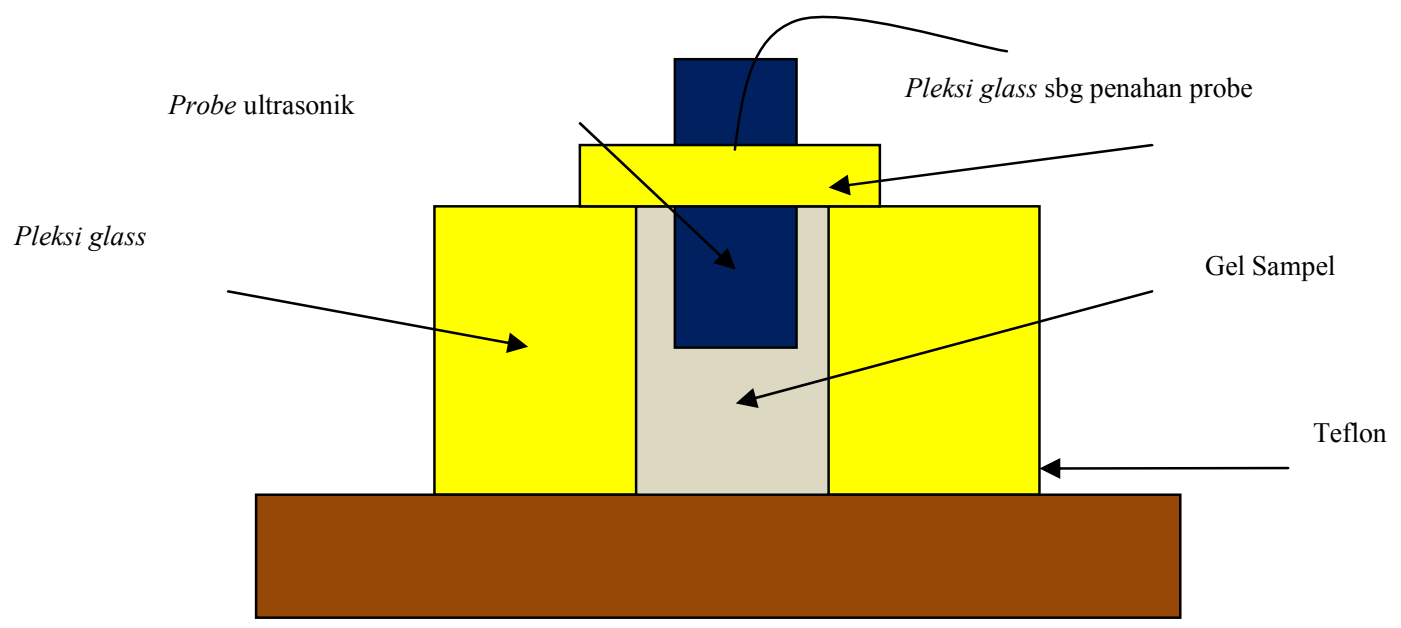

Gambar 2. Set Up Percobaan Pengukuran Cepat Rambat Ultrasonik Dalam Gel.
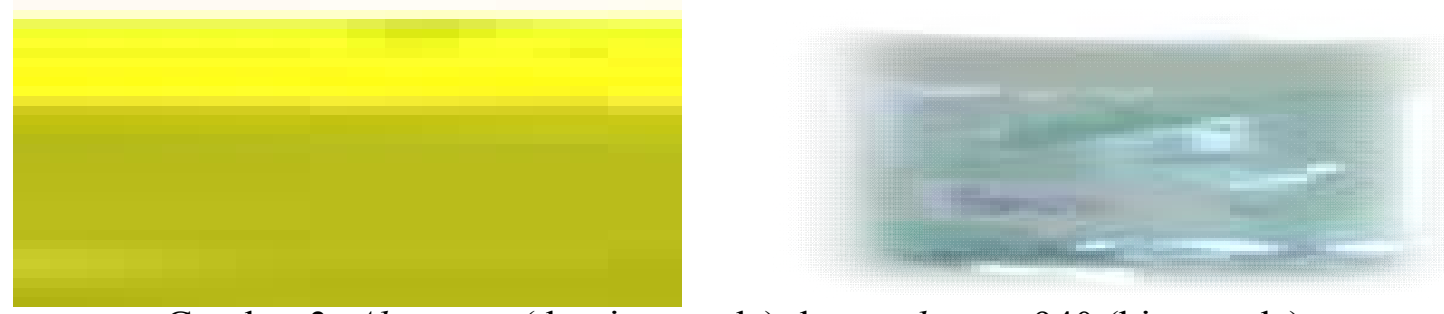

Gambar 3. Aloe vera ( kuning muda) dan carbomer 940 (biru muda).

$\mathrm{T}=2 \mathrm{Z}_{2} /\left(\mathrm{Z}_{1}+\mathrm{Z}_{2}\right)$

Di sini $Z_{1}$ impedansi akustik gel, $Z_{2}$ impedansi akustik tubuh, $\rho$ rapat jenis gel, $\mathrm{C}$ kecepatan rambat gelombang ultrasonik dalam gel. Pengukuran cepat rambat dilakukan dengan metode transmit time (Vogler, 1999). Set up percobaan ditunjukkan pada gambar 2 dengan memasukkan gel sampel kedalam holder. Holder dibuat dari bahan pleksi glass dengan tebal $5 \mathrm{~mm}$ dan diameter $6 \mathrm{~mm}$. Dalam pengukuran ini digunakan alat ultrasonics thickness gauge AR860 dengan frekwensi dan diameter probe masing - masing sebesar $5 \mathrm{MHz}$ dan $5 \mathrm{~mm}$.
Pengukuran dilakukan pada minggu pertama dan minggu kedua belas. Ini dimaksudkan untuk mengetahui ada tidaknya perubahan gel terhadap waktu.

\section{DATA DAN PEMBAHASAN}

Sari aloe vera berwarna kuning muda dengan densitas sekitar $1 \mathrm{gr} / \mathrm{cm}^{3}$. Dan Carbomer berwarna biru muda dengan densitas $1,2 \mathrm{gr} / \mathrm{cm}^{3}$. Ketika dicampurkan terjadi perubahan warna sesuai prosentasi aloe vera yang ditambahkan. Hasil pencampuran menghasilkan perubahan warna seperti tampak pada gambar 4 . 


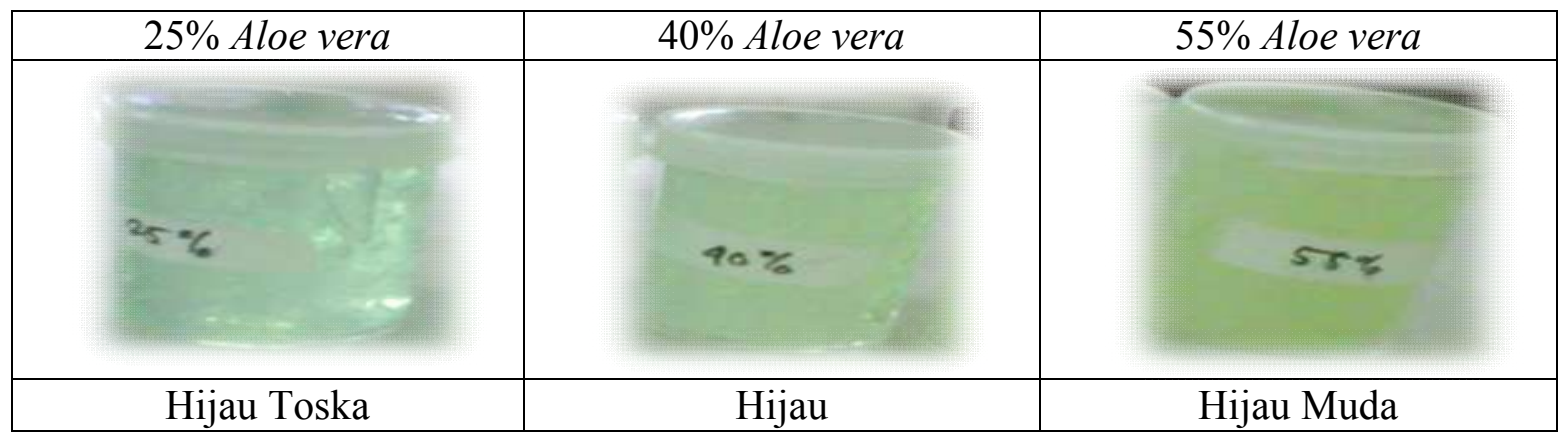

Gambar 4. Gel USG Berbasis Carbomer 940 Dengan Penambahan Aloe Vera 25\%, $40 \%$, dan $55 \%$.

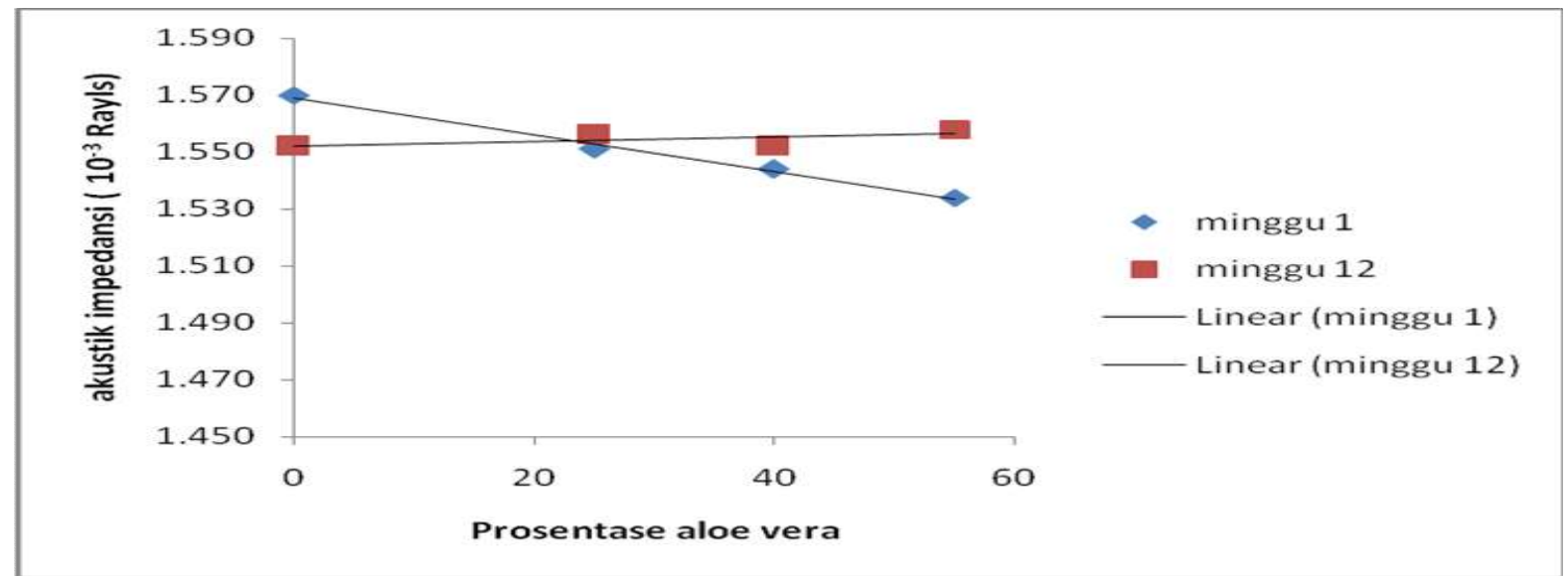

Gambar 5. Hasil Pengukuran Impedansi Akustik Penambahan Aloe Vera Ke Dalam Gel Carbomer 940.

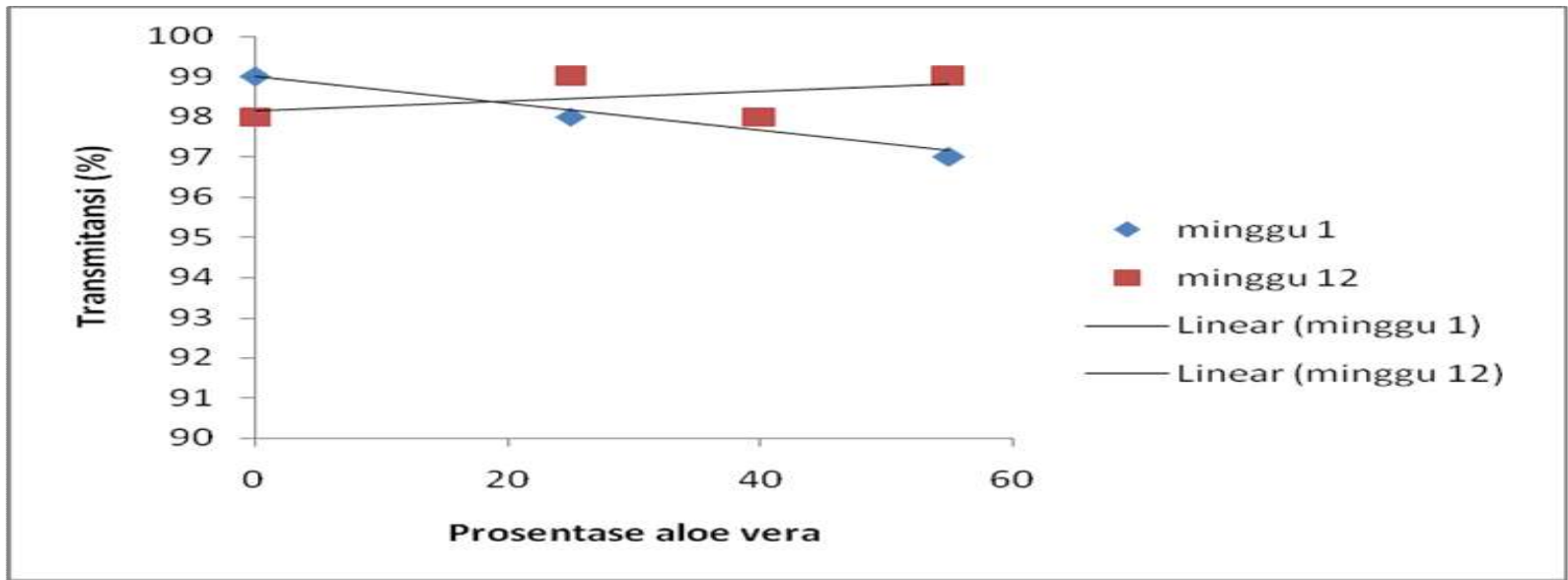

Gambar 6. Hasil Perhitungan Koefisien Transmitansi Pencampuran Aloe Vera + Carbomer 940 Ketika Diaplikasikan Pada Permukaan Tubuh.

Pada gambar 5 diperlihatkan nilai impedansi akustik hasil penambahan aloe vera ke dalam carbomer 940 pada minggu 1 dan minggu ke 12. Pada minggu 1 terjadi kecenderungan penurunan nilai dari 1,570 Mrayls hingga 1534 MRayls.
Densitas aloe vera yang lebih rendah dari pada carbomer 940 menyebabkan hasil pencampuran menjadi lebih cair sehingga kecepatan ultrasonik dalam gel mengalami penurunan. Dengan demikian nilai impedansi akustik juga cenderung mengalami penurunan. 

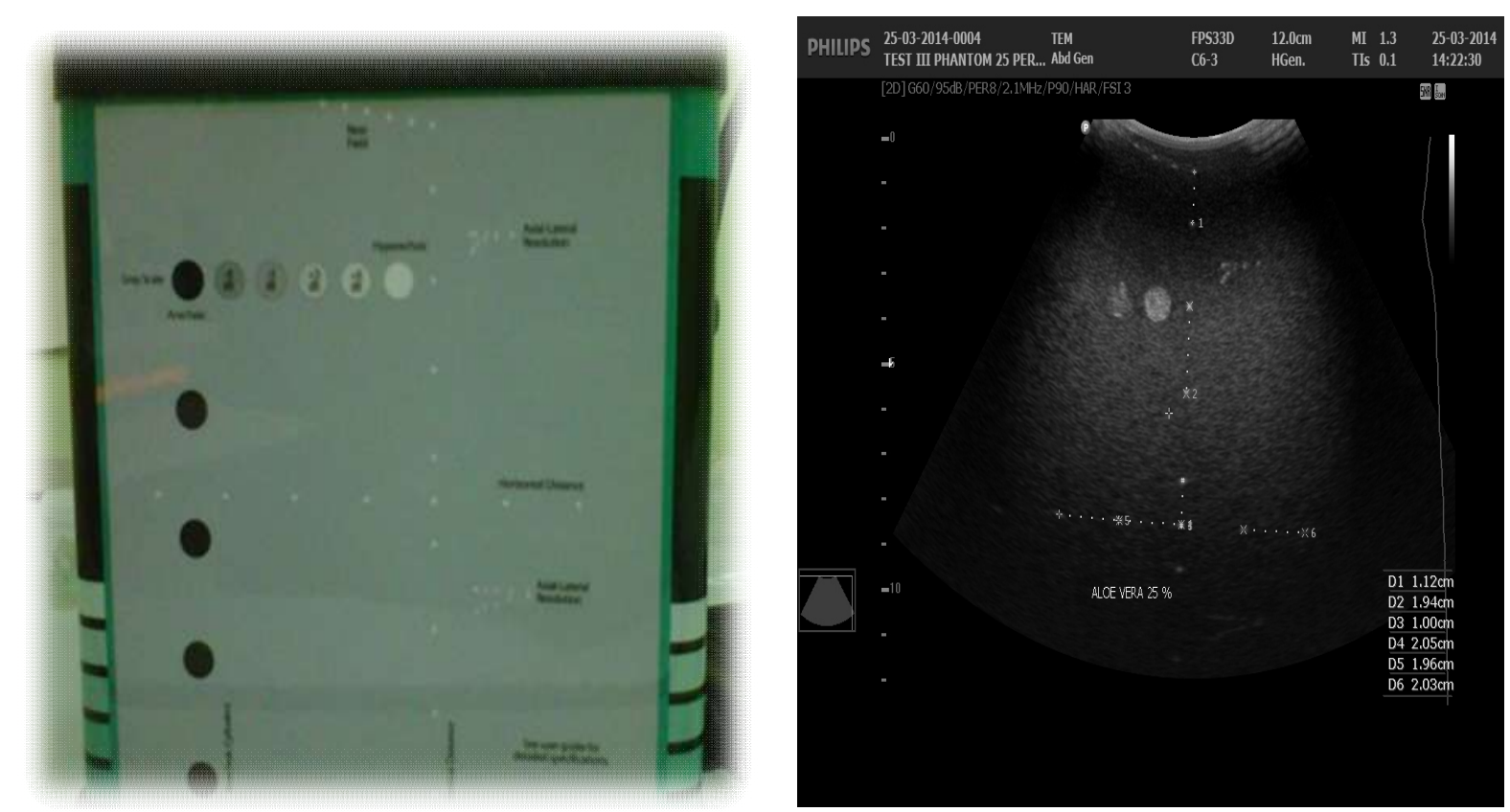

Gambar 7. Phantom CIRS 054G dan Citra USG Pengujian Gel Aloe Vera (25\%)

$$
\text { + Carbomer } 940 .
$$

Sebaliknya pada minggu ke 12 hasil pengukuran nilai impedansi relatif tidak berubah. Barang kali ini disebabkan adanya penguapan cairan selama penyimpanan. Secara fisik pun hasil pencampuran lebih kental dibanding saat minggu pertama.

Begitu pula pada perhitungan koefisien transmitansi ketika di aplikasikan pada permukaan tubuh. Mengingat nilai impednasi akustik tubuh sekitar 1,5 Mrayls dan dengan menggunakan persamaan 2 maka diperoleh hasil seperti ditunjukkan gambar 6 .

Pada pengujian minggu pertama transmitansi menurun dari $99 \%$ menjdi $97 \%$ seiring penambahan aloe vera. Namun pada minggu ke 12 nilai tarnsmitasni relatif tetap dengan nilai $98 \%$ hingga $99 \%$. Dari penguijian menggunakan citra USG dengan phantom CIRS 054G rata - rata diperoleh akurasi aksial diatas 95\% dan lateral ditas 98\%. Contoh citra USG dan phantom CIRS 054G ditunjukkan pada gambar 7 .

\section{KESIMPULAN}

Penambahan aloe vera pada gel carbomer 940 secara fisik merubah warna gel. Penambahan aloe vera diatas $55 \%$ membuat gel lebih cair hingga tidak comfortable ketika digunakan. Hasil pengukuran akustik impedansi dan perhitungan transmitansi pada minggu pertama menunjukkan nilainya cenderung menurun namun pada minggu ke 12 relatif nilainya tidak berubah. Hasil pengujian citra USG dengan phantom CIRS 054G rata - rata diperoleh akurasi aksial diatas 95\% dan lateral diatas $98 \%$.

\section{Ucapan Terimaksih}

Di ucapkan terima kasih kepada sdr Ahmadi mahasiswa paska sarjana fakultas biomedis Universitas Indonesia (UI) serta pimpinan fakukltas biomedis UI atas kerjasamanya selama ini. 


\section{DAFTAR PUSTAKA}

Christine L,et all, 2006. Total carbo-mer of benzene, its carbo-trannulate form and the zig zag nanotube there of, J.Org Chem, 71(17), pp 6317-6324.

Krautkramer J, et al, 1990. Ultrasonics testing of materials, 4th revised edition, Springer Verlag,Nov.

McDicken.W.N, $1976 . \quad$ Diagmostic ultrasonics: principle and use of instrument, John wiley \& Sons.

Susan C,et al, Infection associated wit the use of ultrasound transmission gel : proposed guideline to minimize risk, Infection Control and Hospital Epidemology, 2012:33(12).

Vogler B.K, 1999. Aloe vera : a system review of its clinical effectiveness, British journal of general practice, october. 